\title{
Features of calculations for arc quenching reactors with non- magnetic gaps in core of magnetic circuit
}

\author{
Ildar Bayazitov ${ }^{1}$, Rustem Galimzyanov ${ }^{1}$, Vjacheslav Medvedev ${ }^{2},{ }^{*}$ and Mikhail Petrov ${ }^{3}$ \\ ${ }^{1}$ JSC "Network Company", a branch of Privolzhskie Electric Networks, 420000 Kazan, Russia \\ ${ }^{2}$ FSBEI HE "Chuvash State University named after I.N. Ulyanov ", 428000 Cheboksary, Russia \\ ${ }^{3}$ LLC "NIR Energo", 428000 Cheboksary, Russia
}

\begin{abstract}
This article presents the results of comparative studies of existing methods to calculate the inductance of dynamic and static single-phase reactors of arc extinguishing by double-rod and armored magnetic circuits with non-magnetic gaps in terms of the geometric parameters of the device. There are proposed expressions to correct the determination of the effective area of the winding of reactors by the shunting magnetic flux. On the basis of numerical calculations, the significant influence of the correct calculation of the effective area of the reactor winding by the shunt magnetic flux on the result of calculating the inductance is shown, it undoubtedly affecting the accuracy of the operation of both many digital devices of existing substations in particular, and new digital substations being introduced in general. It was also found in the work, that carrying out the correct calculation will improve both electrical characteristics of the device, and technical economic indicators of capacitive current compensation systems as part of digital substations, when setting the inverse problem of determining the geometric dimensions of the electrical part of the reactor according to the known inductance value, which depends and is calculated on the parameters of the given network, including capacitive currents.
\end{abstract}

\section{Introduction}

It is known that in ensuring the reliable operation of medium voltage high-voltage networks the role of electric reactors, called Petersen coils [1,2], is of great and fundamental importance in the fight against capacitive currents of the electric network and the consequences of single-phase earth faults. Separately, we note that a little more than 100 years ago, the first scientific works were published in the field of limiting capacitive current and suppressing the earth fault arc using an inductor [1-3], later called an arc suppression reactor.

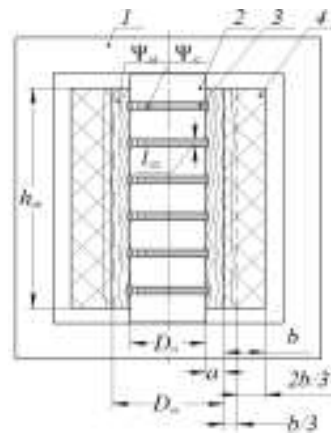

a)

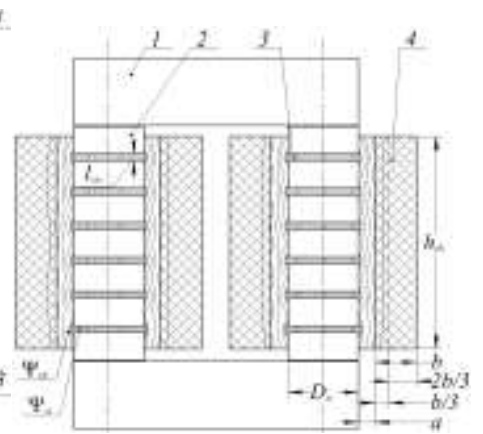

b)
Fig. 1. The structure of an armored rod a) and a double rod b) a single-phase arc suppression reactor with non-magnetic gaps; 1 magnetic core, 2 magnetic rod inserts, 3 non-magnetic gaps, 4 winding.
Can be attributed to the initial work on the calculation of reactors [4-8].

From the scientific literature available to the authors in the field of research of electric reactors, in our opinion, one of the fundamental foreign and domestic studies reflecting the most complete calculation methodology for reactors with a steel magnetic core and gaps (Fig. 1) are determined the works [3-9].

In this article, there is a made attempt to compare the ways and methods to study electric reactors proposed by various authors and applied to reactors with armored and rod magnetic circuits. The necessity for such work arose because of different interpretations by the authors of the calculation formulas and the appearance of "inconsistencies" in the presentation of the same mathematical expressions. The procedure for choosing the analysis of a specific research work is built according to the publication time and publication of the material under study.

It should be noted that here the emphasis is being done on the analysis of methods to determine the inductance from the geometric dimensions of the magnetic circuit and the reactor winding, in particular, on calculating the most effective cross-sectional area of the winding along the path of the shunting magnetic flux [6-10]. Let us agree to adhere to the designations in the figures and the terminology in the text proposed by E.A. Mankin, as well as in the comparative description of the works of other authors, which differ from [9] for the purpose of a uniform perception of this material.

\footnotetext{
* Corresponding author: $\underline{\operatorname{mwg} 71 @ \text { mail.ru }}$
} 


\section{Methods}

The total flux linkage of the reactor consists of the main flux linkage passing through the steel and the shunting flux linkage passing outside the core and it is described by the equation $[9,10]$

$$
\begin{gathered}
\Psi_{\Sigma}=\Psi_{s t}+\Psi_{s h}=w\left[\Phi_{s t}+\Phi_{s h}\right]= \\
=w\left[B_{s t} S_{s t}+B_{s h} S_{s h}\right] \\
\Psi_{\Sigma}=L I_{r}=w\left[B_{z a z} S_{z a z}+B_{s h} S_{s h}\right]=w\left[B_{s t} S_{s t}+B_{s h} S_{s h}\right],
\end{gathered}
$$

where $w$ - is a number of winding turns;

$\Phi_{s t}, \Phi_{s h}-$ is the main and shunting magnetic flux;

$B_{s t}, B_{z a z}, B_{s h}$ - is a magnetic induction in the core (steel), in the gap and outside the steel;

$S_{s t}, S_{z a z}, S_{s h}$ - is the area of the core, the gap and the cross-sectional area of the path shunting the path of the main flow.

Following [9] for you can write $I_{r} w=B_{s h} h_{o b} / \mu_{0}$, where $B_{s h}=\mu_{0} I_{r} w / h_{o b}$ or $B_{s h}=\mu_{0} I_{r} w / n l_{z a z}=B_{s t} S_{s t} / S_{z a z}$ where $\mu_{0}$ is a magnetic constant.

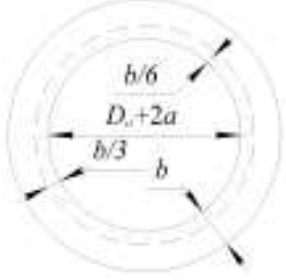

Fig. 2. To determine the area of the reactor winding at a thickness of the inner diameter.

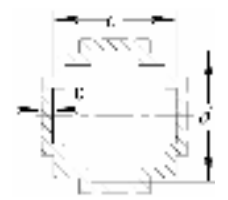

Fig. 3. To the calculation of the rod coefficient $P_{s t}$, taking into account the width of the lateral flow $\varepsilon$.

Then we get $L I_{r}=w\left[B_{s t} S_{s t}+\mu_{0} I_{r} w S_{s h} / h_{o b}\right]$.

On the other hand, the total flux linkage is equal to the product of the inductance of the choke and the current of the reactor.

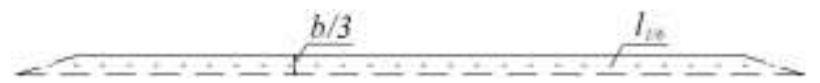

Fig. 4. To calculate the area of the trapezoid equal to the area of the reactor winding at a thickness $b / 3$ of the inner diameter

The inductance of a reactor with uniform gaps through the geometric dimensions of the magnetic circuit from (2) is determined by the expression in accordance with:

$$
L=w\left[\frac{B_{s t} S_{s t}}{I_{r}}+\frac{\mu_{0} w S_{s h}}{h_{o b}}\right] .
$$

Moreover $B_{s t} S_{s t}=B_{z a z} S_{z a z}$ :

$$
\begin{gathered}
L=w\left[\frac{B_{z a z} S_{z a z}}{I_{r}}+\frac{\mu_{0} w S_{s h}}{h_{o b}}\right]=w\left[\frac{\mu_{0} I_{r} w}{n l_{z a z}} \frac{S_{z a z}}{I_{r}}+\frac{\mu_{0} w S_{s h}}{h_{o b}}\right] . \\
L=\mu_{0} w^{2}\left[S_{z a z} / n l_{z a z}+S_{s h} / h_{o b}\right] .
\end{gathered}
$$

where $S_{z a z}=S_{s t}+P_{s t} \varepsilon$ - equivalent core section; $n$ is a number of gaps; $l_{z a z}$ is a length of one gap; $S_{s h}=S_{v n}-S_{s t}-3 P_{s t} \varepsilon / 4+S_{1 / 3} ; S_{v n}=\pi\left(D_{s t}+2 a\right)^{2} / 4$ is an area of a circle by the inner diameter of a round winding; $D_{s t}$ is a core diameter; $S_{s t}$ is a cross section (area) of the core; $P_{s t}=2(c+d+2 \varepsilon)$ is a coefficient of steel; $c, d$ are sides of the core section; $S_{1 / 3}=l_{\text {eff }} b / 3$ is an area of a trapezoid equal to the area of the reactor winding at a thickness $b / 3$ of the inner diameter; $l_{e f f}$ is a winding circumference of the effective zone of the shunt flow section; $\varepsilon$ is a magnetic field bulge in a gap; $a$ is a distance from winding to core; $b$ is a radial dimension (thickness) of the winding; $h_{o b}$ is a winding height.

In formulas (7) and (11) in [9], in the last term in the expression $S_{s h}$, in our opinion, to determine the circumference $l_{\text {eff }}=\pi\left(D_{s t}+2 a+b\right)$, instead of one should write $l_{\text {eff }}=\pi\left(D_{s t}+2 a+b / 3\right)$ [9]. The value $b / 3$ is obtained as $b / 3=b / 6+b / 6$. In this case, when calculating the area $b / 3$ of the winding on a radial dimension, in contrast to [9], the circumference equals to $l_{\text {eff }}=\pi\left(D_{s t}+2 a+2 b / 6\right)$. In fact, the area of the ring with the thickness $b / 3$ shown in Fig. 2 is calculated. With this form of writing the expression $l_{\text {eff }} b / 3$, instead of the area of the ring, an equivalent area is calculated equal to the area of the trapezoid (Fig. 4) with the length of the center line of the trapezoid $l_{1 / 6}$. If we apply the notation in the form $D_{s t}+2 a+b$ according to [9], then the thickness of the ring will be equal not $b / 3$, but $b / 2$, which significantly changes the idea of the most effective influence of the shunting magnetic flux in accordance with [9] on the thickness of the winding $b / 3$ (Fig. 1) with an average circumference on the thickness of the winding $b / 2$. Therefore, after detailed correction $S_{1 / 3}=\pi\left(D_{s t}+2 a+b / 3\right) b / 3$, we finally get:

$$
L=\mu_{0} w^{2}\left[\begin{array}{l}
\left(S_{s t}+P_{s t} \varepsilon\right) /\left(n l_{z a z}\right)+ \\
+\left(S_{v n}-S_{s t}-3 P_{s t} \varepsilon / 4+S_{1 / 3}\right) / h_{o b}
\end{array}\right] .
$$

In the work of Waters [6], referred by the authors of the book $[7,8]$ in the formula (187) on page 346 when calculating the effective magnetic flux through the radial section of the winding, which is subsequently used to calculate the reactor inductance from the geometric parameters of the magnetic circuit and the reactor 
winding, the winding area reactor at a thickness of the inner diameter is defined as

$$
S_{1 / 3}=l_{\text {eff }} b / 3, l_{\text {эфф }}=\pi\left(D_{s t}+2 a+b / 2\right) .
$$

Somewhat different from [9], the method to determine the inductance of the choke with an air gap in the iron core is used in [11]. In terms of determining the cross-sectional area of the path, reduced to the full number of flux linkage, shunting the path of the main flow, as in [9], it contains an expression, as the author points out, for determining the average length of the winding and is designated as $U$, which corresponds $l_{\text {eff }}$ in this article

$$
L=\mu_{0} w^{2}\left[\begin{array}{l}
\frac{S_{z a z}}{n l_{z a z}}+\ln \left(\frac{n^{2}-p^{2}}{n-1}\right) \frac{l_{\text {eff }}}{2 \pi}+ \\
+\left(1-\frac{1}{p}\right) \ln \left(\frac{\left(p^{2}-m^{2}\right) /(1-m)}{\left(n^{2}-p^{2}\right) /\left(n^{2}-1\right)}\right) \frac{2}{3} \frac{l_{e f f}}{2 \pi}
\end{array}\right]
$$

where $n=H_{D} / H_{b}, m=H_{C} / H_{b}, p=h_{o k} / l_{z a z}, h_{o k}$ is a magnetic circuit window height, $H_{D}, H_{D}, H_{D}$ is a magnetic field strength [1111].

Moreover, in [10], the expression for the so-called average length of the winding $U=l_{\text {eff }}$ is not disclosed. By comparing the explanatory figure 13 and the calculated figure 16, it can be seen that the author in [1111], as well as in [9], focuses on the most effective influence of the shunt flux for the calculated value of the inductance of the choke on the thickness of the winding $b / 3$ from the inner diameter of the winding. However, the study of numerical calculations on page 267 [11] in the form of $l_{\text {eff }}=3.14 \cdot(300+2 \cdot 20+2 \cdot 100 / 3)=1298 \mathrm{MM} \approx 1.3 \mathrm{~m}$ shows that the expression for the average length of the winding is defined as $l_{e f f}=\pi\left(D_{\text {ст }}+2 a+2 b / 3\right)$.

If we represent the circumference $U=l_{\text {eff }}$ as the length of the trapezoid midline, then the height of the given trapezoid should be equal to $2 b / 3$. The calculations checking of $S_{1 / 3}$ to Figure 16 in [1111] showed that $S_{1 / 3}=3.14\left(413.2^{2}-340^{2}\right) / 4=43280.38 \mathrm{~mm}^{2}$,

however, the equivalent area of the trapezium according to [10], in our opinion should be equal to $S_{1 / 3}=3.14 \cdot(300+2 \cdot 20+110 / 3)=43280.38$, instead of $S_{1 / 3}=3.14 \cdot(300+2 \cdot 20+110 \cdot 2 / 3)=47501.92$.

In [1212], fully referring to the methods of determining the inductance of the inductor from the geometric dimensions of the magnetic circuit and the winding, proposed in [1111], the author discloses an expression to find the average circumference by designating as $A=U$, i.e. $A=l_{\text {eff }}$, at the thickness $b / 3$ of the inner diameter of the winding, being equal to the length of the center line of the trapezoid in the form of $l_{\text {eff }}=\pi\left(D_{\text {ст }}+a+b / 3\right)$. In the formula (5) of work
[1212], in our opinion, there is a misprint, which consists in the absence of a coefficient 2 in front of the distance $a$ from the core to the winding. When correcting the expression for $U$ in [10] according to the expression for $A$ given in [1212] and adding the missing coefficient, the length of the center line of the winding on the thickness $b / 3$ is calculated correctly, which in its turn affects the final result of finding the inductance value $L$. However, analyzing papers [1111] and [1212], it should be noted that when calculating the area $S_{1 / 3}$, the length of the effective midline of the trapezoid $l_{\text {eff }}$ is multiplied not by the value $b / 3$, as shown in [9], but expressed through a logarithmic function, which is not the subject of discussion in this article.

In [1313-15], the expression for the length of the effective centerline of the working winding of the reactor is $l_{\text {eff }}=\pi\left(D_{\text {ст }}+2 a+b / 2\right)$, where $b / 2$ is obtained as $b / 2=b / 4+b / 4$. In this case, the height of the trapezoid to determine the area $S_{1 / 3}$ is equal to $b / 3$.

The work [1616] is devoted to the study of grounding arc suppression reactors with smooth regulation of inductance, in which there is an expression of the form $D+a+b / 3$ in formulas (9) and (10) to determine the length of the effective center line of the working winding of the reactor. Comparative analysis of formulas (9), (10) in Fig. 1 in [1616] shows that the quantity $D$ contains the value of the rod diameter and two halves of the distance from the rod to the winding, i.e. in formulas (9) and (10) of [1616] $D=D_{s t}+a$ in comparison with this article $l_{\text {eff }}=\pi\left(D_{s t}+2 a+b / 3\right)$. Note that, in [1616], the authors refer to $[9,1111,1212]$, there is a misprint in the work, in our opinion, the value $\pi$ is missed.

The inductance of the winding of one rod with uniform gaps within the winding, depending on the geometric dimensions of the rod and the gaps in accordance with [1717, p. 281], is determined as

$$
L=\mu_{0} w^{2}\left[S_{z a z} / n l_{z a z}+\left(S_{b / 3}-S_{s t}-3 P_{s t} \varepsilon / 4\right) / h_{o b}\right]
$$

When describing the formula (9-94) from [1717], although the author of the book refers to work [9] from the bibliography of this article, however, he does not disclose the form for the variable $S_{b / 3}$, stipulating that this is the area of a coil spaced one third of the thickness of winding $b$ from the inner turn [1414]. Following this description in [1717], one can presumably accept $S_{b / 3}=\pi\left(D_{s t}+2 a+2 b / 3\right)^{2} / 4$, or, following (4) of the present work, $\quad S_{b / 3}=S_{v n}+S_{1 / 3}$; $S_{b / 3}=\pi\left(D_{s t}+2 a\right)^{2} / 4+\pi\left(D_{s t}+2 a+b / 3\right) b / 3$. Both of the latest entries have the same geometrical meaning and are equal to each other.

When calculating the inductance of a double-rod reactor with gaps in formula (5) in [1818] for calculating flux linkage or self-inductance, the expression for the equivalent (given) area of the scattering channel $S_{1 / 3}$ is given as 


$$
S_{1 / 3}=\pi(d-2 b / 6)^{2} / 4,
$$

where, according to the explanations in Fig. 2 of works [1818] $d=D_{s t}+2 a+2 \cdot 2 b / 3$. However, when substituting this expression instead of $d$ in (7), we obtain: $\quad S_{1 / 3}=\pi\left(D_{s t}+2 a+b\right)^{2} / 4$, which does not correspond to the explanation of the effective scattering area on the thickness $1 / 3$ of the winding from the inner diameter in accordance with $[6,8,9]$. Therefore, in (7), according to our assumption, it is necessary to correct either $d=D_{s t}+2 a+b$, or instead of writing $2 b / 6$, one should apply $2 b / 3 \mathrm{t}$ in order to obtain the correct expression in the form $S_{1 / 3}=\pi\left(D_{s t}+2(a+b / 3)\right)^{2} / 4$ in formula (7) in [1818]. Due to the ambiguous recording of the expression for $S_{1 / 3}$ with explanations in Fig. of work [1818], we introduce the calculations according to [1919], which correspond to our explanations above.

In the works of recent years, for example, in [1919], the inductance of the reactor is determined through the turns, the dimensions of the turns and the rod in the same way as in (6) of this work, where $S_{1 / 3}=\pi\left(D_{s t}+2(a+2 b / 3)\right)^{2} / 4$ is the cross-sectional area of the turns (windings) is equivalent in flux linkage. In this case, the record in the form $2 b / 3$ is valid due to the fact that the area of the circle is calculated without taking into account the equivalent area of the trapezoid, which was explained by formula (6) of this work. We also note that in the formula for calculating the inductance of the reactor in [1919], there seems to be a misprint in the choice of designation for the calculation of the gap area.

In [19], in formula (6) $S_{1 / 3}=l_{\text {eff }} z, z=\delta_{k} / 4+b / 3$ where $l_{\text {eff }}=\pi\left(D_{\text {st }}+2 a+b\right)$. The height of the equivalent trapezoid in formula (6) in [20Ошибка! Источник ссылки не найден.] is given as $z$, but the author does not explain the purpose of the value $\delta_{k}$. As it was noted in the analysis of works [9-1212, 13131919], in the expression $l_{\text {eff }}$ one should write $b / 3$ instead of the value $b$. However, replacing $b$ to $b / 3$ is insufficient due the fact that the height of the equivalent trapezoid in [200шибка! Источник ссылки не найден.] is equal to $z$. Therefore, the refined expression for calculating the area of the winding on its thickness $b / 3$, taking into account $\delta_{k} / 4$, according to our assumption, should be equal to $S_{1 / 3}=\pi\left(D_{s t}+2 a+z\right) z$.

Before carrying out numerical calculations, we note that this work reflects the results of only some of the materials from existing scientific articles to determine the inductance of rod and armored reactors with gaps, taking into account the effective area of the shunting part of the winding from its inner diameter in order to explain the effect of the type of the effective part of the transverse area of the reactor winding on the final result of the inductance value.

\section{Comparative verification calculations}

The numerical values of the parameters of the core and the winding of the reactor are taken as in [9] as $D_{s t}=150 \mathrm{~mm}, a=22 \mathrm{~mm}, b=17 \mathrm{~mm}$.

In case of different representations of the effective thickness of the reactor winding in the zone of the shunting magnetic flux, the calculation results $l_{e f f}$ are listed in Table 1. Accept $l_{\text {eff } 1}=\pi\left(D_{s t}+2 a+b / 3\right)$.

Table 1. Results of comparative calculations $l_{\text {eff }}$

\begin{tabular}{|c|c|c|c|}
\hline № & Expression $l_{\text {eff }}$, № of work & $\begin{array}{c}\text { Value } \\
l_{\text {eff }}, \mathrm{mm}\end{array}$ & $\begin{array}{c}\Delta l_{\text {eff }}, \\
\mathrm{mm}\end{array}$ \\
\hline 1 & $\begin{array}{c}\pi\left(D_{s t}+2 a+b / 3\right), \\
\text { for this work, [1212, 1616] }\end{array}$ & 626.95 & - \\
\hline 2 & $\begin{array}{c}\pi\left(D_{s t}+2 a+b\right),[9 \text { Ошибка! } \\
\text { Источник ссылки не } \\
\text { найден., 20Ошибка! Источник } \\
\text { ссылки не найден.] }\end{array}$ & 662.54 & 35.58 \\
\hline 3 & $\begin{array}{c}\pi\left(D_{s t}+2 a+2 b / 3\right),[11] \\
4\end{array}$ & 644.74 & 17.79 \\
\hline 5 & $\pi\left(D_{s t}+2 a+b / 3\right),[1212]$ & 593.46 & 33.4933 \\
\hline$\left(D_{s t}+2 a+b / 2\right),[6,8$, & 635.85 & 8.89 \\
\hline
\end{tabular}

In table 1, the error in calculating the length of the center line of the trapezoid on the thickness of the winding $b / 3 \quad \Delta l_{\text {eff }}=\left|l_{\text {eff }}-l_{\text {eff_- }}\right|$.

Table 2 contains the results of calculations $S_{1 / 3}$, in which the method proposed in [6-9], is applied using the value $b / 3$ instead of calculating the values of logarithmic functions according to [1111-16].

Table 2. Results of some comparative calculations $S_{1 / 3}$.

\begin{tabular}{|c|c|c|c|}
\hline № & Expression $S_{1 / 3}$, № work & $\begin{array}{c}S_{1 / 3}, \\
\mathrm{~mm} 2\end{array}$ & $\begin{array}{c}\Delta S_{1 / 3}, \\
\mathrm{~mm} 2\end{array}$ \\
\hline 1 & $\begin{array}{c}\pi\left(D_{s t}+2 a+b / 3\right) b / 3, \\
\text { for this work, }[1010,1616]\end{array}$ & 3552.73 & - \\
\hline 2 & $\begin{array}{c}\pi\left(D_{s t}+2 a+b\right) b / 3,[9 \text { Ошибка! } \\
\text { Источник ссылки не найден.] }\end{array}$ & 3754.39 & 201.65 \\
\hline 3 & $\pi\left(D_{s t}+2 a+2 b / 3\right) b / 3,[1111]$ & 3653.56 & 100.81 \\
\hline 4 & $\pi\left(D_{s t}+a+b / 3\right) b / 3,[1212]$ & 3362.94 & 189.79 \\
\hline
\end{tabular}




\begin{tabular}{|c|c|c|c|}
\hline 5 & $\begin{array}{c}\pi\left(D_{s t}+2 a+b / 3\right) b / 3,[6,8, \\
1313-15]\end{array}$ & 3603.15 & 50.41 \\
\hline 6 & $\begin{array}{c}\pi\left(\left(D_{s t}+2 a+2 b / 3\right)^{2}\right) / 4-,[1818, \\
-\pi\left(D_{s t}+2 a\right)^{2} / 4 \\
1919]\end{array}$ & 3552.73 & 0.00 \\
\hline 7 & $\begin{array}{c}\pi\left(D_{s t}+2 a+b\right) z, \text { at } \delta_{k}=0.5, \\
{\left[\begin{array}{c}\text { 20Ошбка! Источник ссылки не } \\
\text { найден.] }\end{array}\right.}\end{array}$ & 3837.21 & 284.475 \\
\hline
\end{tabular}

Accept $S_{1 / 3 \_1}=\pi\left(D_{\text {ст }}+2 a+b / 3\right) b / 3$. In table 2, the error in calculating the area of the winding on the thickness $\Delta S_{1 / 3}=\left|S_{1 / 3}-S_{1 / 3 \_}\right|$.

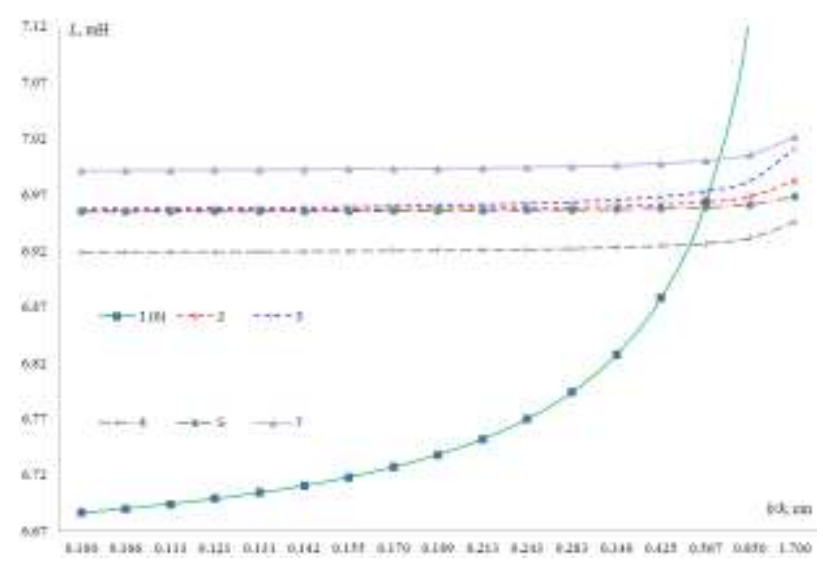

Fig. 5. Dependence of $L$ on $S_{1 / 3}$.

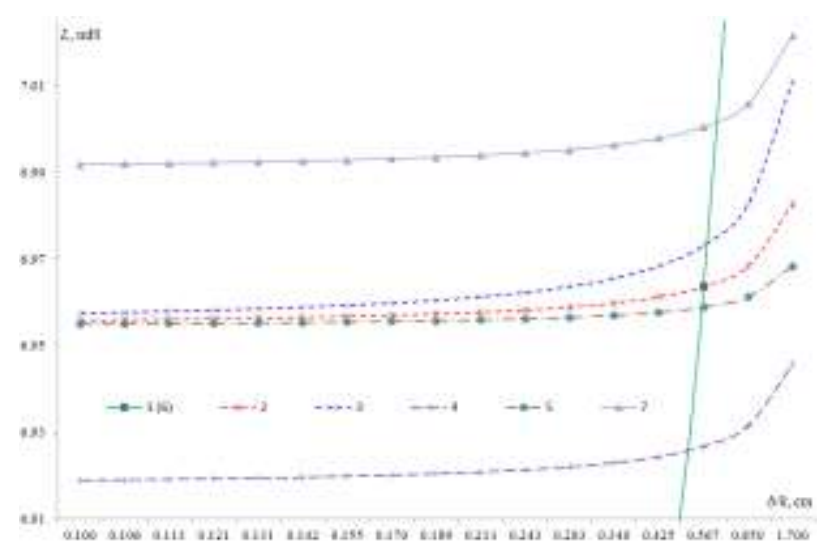

Fig. 6. Dependence of $L$ on $S_{1 / 3}$ in the scale of change $L=[6.91 . .7 .01]$.

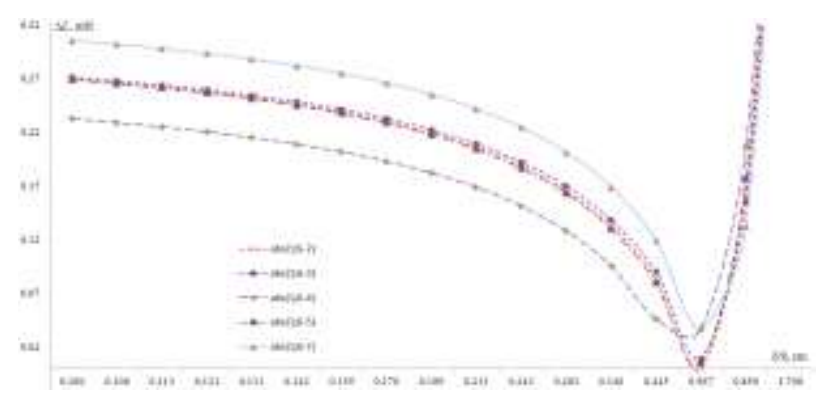

Fig. 7. Errors in calculating $L$ according to various reduced models on a scale of change $\Delta L=[0 . .0 .3]$.

\section{Conclusions}

Calculation $L$ of the dependence $\left(n l_{z a z}\right)$ on for different expressions $S_{1 / 3}$ shows that the effect $S_{1 / 3}$ is noticeable with an increase in the total height (length) of the gaps, as well as/or with a decrease $h_{o b}$ (Fig. 5 - 7). The results of the obtained calculations could be useful both in the design of new arc suppression reactors and in their study, for example, in such works as [2120 - 282828].

\section{References}

1. W. Petersen, "Der aussetzende Erdschluss", ETZ, Bd 38, 553-555; ETZ, Bd 47, 564-566; ETZ, Bd 48 (1917)

2. W. Petersen, "Limitation of earth current and suppression of earth fault arcs by the earthing coil", ETZ Elektrotechnische Zeitschrift, vol. 40 (1919)

3. W. Petersen, Forschung und Technik. Verlag Julius Springer, Berlin, 576 (1930)

4. G.V. Butkevich, V.V. Mikhailov, I.I. Rothaus Reactors. - M. - L .: Gosenergoizdat, 184 (1933)

5. R. Willheim, Das Erdschlufiproblem in Hochspannungsnetzen. Berlin, Verlag von Julius Springer, 342 (1936)

6. M. Waters, The calculation of flux, losses and forces in ironcored reactors with distributed air gaps, EI. Res. Assoc., London, Report Q/T 137, 12 (1952)

7. R. Willheim, M. Waters, R. Rudenberg, Neutral Grounding in High-Voltage Transmission. Elsevier Science Ltd, 670 (1956)

8. R. Wilheim, M. Waters, Grounding neutrals in highvoltage systems. - M. - L .: Gosenergoizdat, 415 (1959)

9. E.A. Mankin, Calculation of reactors with a steel magnetic core and gaps. // Electricity, 7, 35 - 40 (1959)

10. A.A. Kuzmin, V.V. Medvedev, M.I. Petrov, I.G. Khadyev, On the issues of evaluating the parameters of the active part of the arc suppression reactor with distributed gaps // Bulletin of the Chuvash University. - 2019, 3, $119-126$ (2019)

11. J. Kulda, Induktivitat einer drosselspule mit luftspalt im esenkern, Acta technica, 3, 251 - 270 (2019)

12. R. Antonova, Defined on the working air gap in the arrester bobbin with a movable core by means of ECIM. Electroindustry and instrumentation, 2, 56-59 (1972)

13. L.I. Piletskiy, Maximum power of rod-type smoothing chokes. Bulletin of the Tomsk Order of the October Revolution and the Order of the Red Banner of Labor of the Polytechnic Institute named after S.M. Kirov, 210, 61 - 65 (1974)

14. M.A. Biki, E.A. Yurchenko, Calculation of the inductance of armored reactors // Electrical Engineering. 4, 10 - 12 (1978) 
15. M.A. Biki, Optimization of parameters of high voltage smoothing reactors. Electrotechnical industry. Ser. High voltage devices, transformers, power capacitors. Issue. 2 (94), 16 - 20 (1979)

16. V.D. Golovchan, N.V. Burak, S.D. Gilman, Grounding arc suppression reactors with smooth inductance control. Electrical engineering, 7, $21-24$ (1980)

17.L.V. Leites, Electromagnetic calculations of transformers and reactors. - Moscow: Energiya, 392 (1981)

18. N.A. Blavatskaya, L.V. Leites, Calculation of the web-ampere characteristics of reactors using magnetic circuit circuits. Elektrotekhnika, 5, 41 - 46 (1985)

19. V.F. Ivankov, Synthesis of the first design of optimal design of electric reactors with gaps in the shearing magnetic line. Tekhnichna elektrodinamika, 3, $66-$ 70 (2008)

20. K. Stoikov. Electromagnetically measuring at the current-limiting reactor with a magnetic circuit, a magnetic circuit and air interconnection for work with a transformer for a voltage of $400 \mathrm{kv}$. Godishnik at TU - Sofia. 62, 3. 133 - 140 (2012)

21. S.S. Girshin, V.N. Goryunov, E.A. Kuznetsov, E.V. Petrova, D.S. Osipov, Simulation of Electrical Loads for the Steady-State Regime Calculation of Electric Grids with Arc Extinguish Reactor. Elektro 11th international conference, 290-293 (2016)

22. Y. Liu, M. Tian and J. Yin, Winding current calculation and harmonic analysis of controllable reactor of transformer type. Australian Journal of Electrical and Electronics Engineering, 13, 1, 14-23 (2016)

23. J. Meng, W. Wang, X. Tang, X. Xu, Zero-sequence voltage trajectory analysis for unbalanced distribution networks on single-l ine-to-ground fault condition. Electric Power Systems Research, 161, 1725 (2018)

24. W. Wang, X. Zeng, L. Yan, X. Xu, \& J. M. Guerrero, Principle and Control Design of Active GroundFault Arc Suppression Device for Full Compensation of Ground Current. I E E E Transactions on Industrial Electronics, 64 (6), 4561-4570 (2017)

25. H. Ni, P. Ding, Y. Ma, S. Ai, F. Ma, Q. Zhang, Problems and countermeasures of arc suppression coil in $10 \mathrm{kV}$ distribution system. Archives of electrical engineering, 68 (1), 135-146 (2019)

26. D.A. Matveev, A.V. Zhuikov, I.I. Nikulov, A.Yu. Skorokhodova, S.I. Khrenov, Efficiency assessment of arc suppression reactors based on the energy criterion carried out on a test bench. Russian Electrical Engineering, 87, 431-438 (2016)

27. B. Xu, J. Zhang, X. Cai, H. Qin, D. M. Xi, Przegląd elektrotechniczny, 89, 213-217 (2013)

28. J. Peyman, E. Hamid, S-P Majid, Sizing Neutral Reactor Regardless of Line Length in Shunt Compensated Transmission Lines. 31th Power System Conference, 1-7 (2016) 